Cell Research (2003); 13(1):1-7

http://www.cell-research.com

MINIREVIEW

\title{
New insights into the immunology and evolution of HIV
}

\author{
Justin STEBBing, Steve PATTERSON, Frances GOTCH \\ Department of Immunology, Division of Investigative Science, Faculty of Medicine, Imperial College of \\ Science, Technology and Medicine, The Chelsea and Westminster Hospital, 369 Fulham Road, London \\ SW10 9NH, United Kingdom
}

\begin{abstract}
Fewer than one million HIV infected individuals are currently receiving anti-retroviral therapy. The limitations of such treatment have underscored the need to develop more effective strategies to control the spread and pathogenesis of HIV. Typically, naturally occurring protective immune responses provide the paradigm for such development. It is now clear however that HIV can utilise the millieu of an activated immune system to its own replicative advantage. Mobilisation of the immune response, intended to thwart the virus, may instead fuel its dissemination, 'immune escape' and spread. The immense genetic variation of HIV contributes to lack of immune control and the development of progressive disease in the majority of infected, untreated individuals. Further delineation of the intimate interactions between the HIV and the immune system will be critical and recent advances in this direction are discussed.
\end{abstract}

Key words: HIV, immune response, CTL, evolution, vaccine.

The dissemination of HIV-1 in humans over the last 4 decades represents a catastrophic example of genome transmission and expansion. Over 60 milli on individuals have been infected leading to nearly 20 million deaths and 20 million orphaned children [1-4]. As most of the 16,000 individuals newly infec ted each day live in developing countries where ant i-retrovirals are not readily available, the phrase 'liv ing with AIDS' can be replaced by the statement ' $d$ ying from treatable HIV infection' characterised b $\mathrm{y}$ the relentless decline in both the number and fun ction of HIV specific CD4+ T helper cells which are preferentially infected[5]. In those for whom it is av ailable, highly active antiretroviral therapy (HAAR

\footnotetext{
* Corresponding author: Dr. Justin STEBBING

Department of Immunology, The Chelsea and Westminster Hospital 369 Fulham Road, London SW10 9NH,United Kingdom. Tel: +00 $442087468251 \quad$ Fax: +00 442087465997

E-mail: j.stebbing@ic.ac.uk
}

T) has reduced short-term mortality and markedly i ncreased quality of life by preventingopportunistic diseases. Despite the initial optimism concerning th is selective targeting of the HIV reverse transcripta se and protease[6](see front cover), HAART is asso ciated with clinical side effects, drug resistance[7], a nd does not appear able to target the latent reservo ir of the virus. Fig 1 illustrates the life cycle of HIV1 with reference to current and future therapeutic $t$ argets one of which is shown on the cover.

The interaction between hosts and their infecting pathogens has been likened to a race. Here, the opponent appears able to run very fast indeed[8,9]. Misincorporation, insertion, deletion, or duplication of nucleotides occurs during reverse transcription with a frequency of $10^{-4}$ to $10^{-5}$, owing to a lack of $3^{\prime} \rightarrow 5$ ' exonuclease 'proof reading' activity. This error frequency, the virion production of in excess of $10^{9}$ virions per day in vivo, the large number of 
affected individuals and the persistence of infection, affords HIV-1 tremendous scope for the generation of viral diversity at 6 orders of magnitude greater than that observed for mammalian gene families. Developing more effective prophylactic and therapeutic strategies against a highly mutable virus that is integrated into the genome of a crucially important population of cells poses the major medical challenge of this century[10-12]. Increasing attention is being given to developing regimens that not only control replication but actually restore immune competence in those infected[13]. This would undoubtedly be enhanced by a better understanding of HIV pathogenesis.

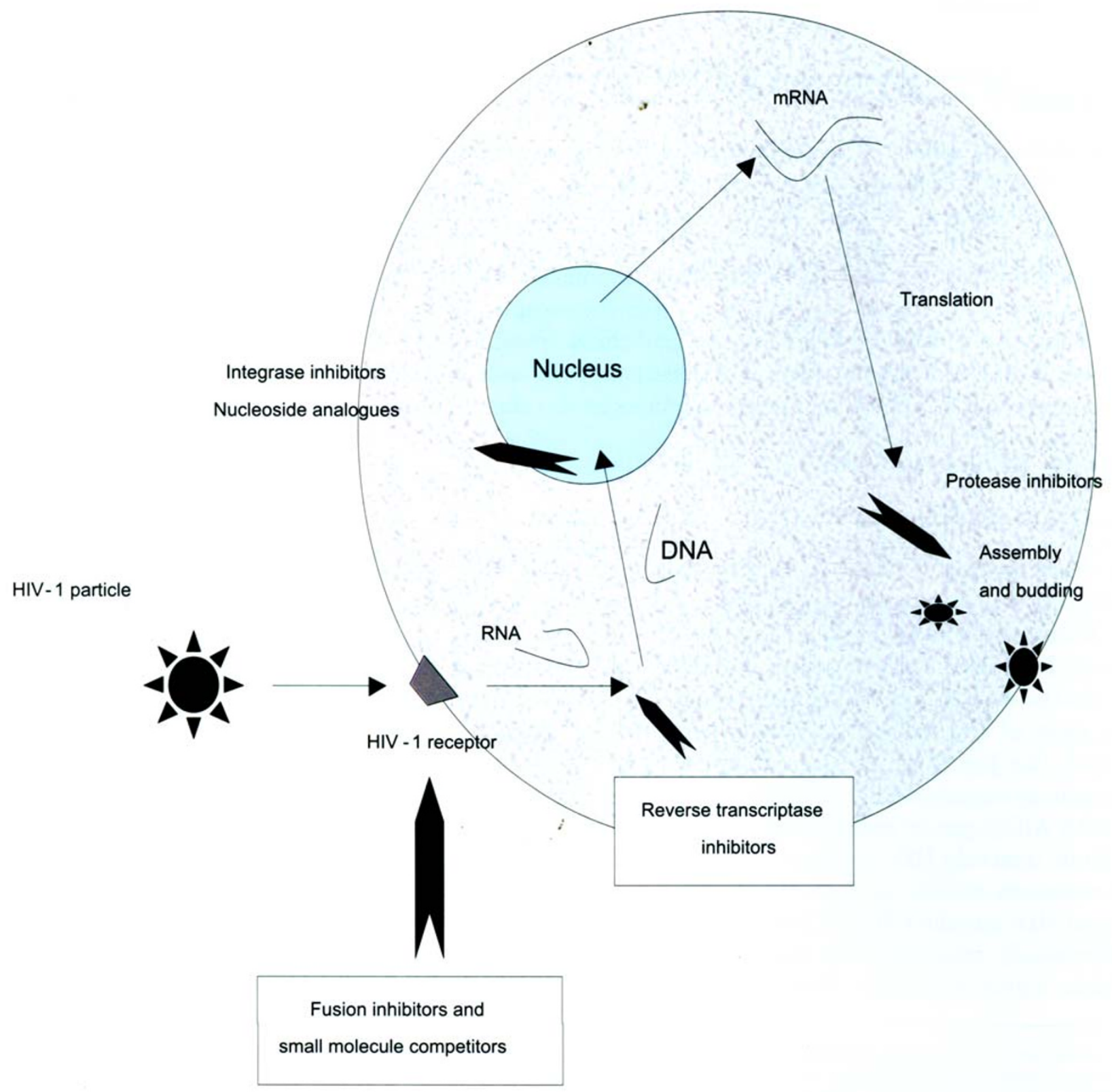

Fig 1. The life cycle of HIV-1 and sites of action of anti-retroviral drugs. New therapies include fusion and integrase inhibitors and small molecules that compete with receptor binding of HIV-1. 


\section{The immune response to HIV-1}

One major issue hindering progress toward an effective vaccine to prevent or modulate HIV-1 infection is that the critical features needed for a protective immune response are not fully understood [13]. Although potent neutralising antibodies can protect against experimentally acquired infection in animal models, they are rarely generated in vivo in the infected person, and neutralisation-resistant viral variants develop rapidly in chronic infection. It is generally agreed that cellular immune responses, particularly specific cytotoxic T lymphocytes (CTLs), are important in the host response to HIV-1. This was shown by a rapid upsurge in viral replication in macaques depleted of CD8+ T cells, in both acute [14] and chronic SIV infection. CTLs develop very early in acute HIV-1 infection, coincident with a rapid fall in plasma viraemia, and in chronic infection, their levels are inversely related to viral load. Their weapons against HIV-1 include the ability to kill infected cells before new virus progeny are produced and to secrete potent antiviral factors, including chemokines, that compete with HIV-1 for the CCR5 receptor. These properties are not CTL specific, but the ability to recognize infected T cells through the presentation of viral peptides complexed with class I HLA molecules allows CTLs to home in on sites of active viral replication.

However, the HIV-specific CTL response ultimately fails to control HIV-1 replication. One reason could be the emergence of viral variants that escape CTL recognition. Viral variants with CTL escape mutations in the Simian immunodeficiency virus (SIV) tat gene were detected at high frequency in macaques shortly after infection with cloned SIV [15]. Escape variants also accumulate in HIV-1-infected humans[16](see below). Recent attention has focused on the quality of the HIV-specific CTL response, following observations that LCMV-infected mice deficient in $\mathrm{T}$ cell help generated virusspecific CD8+ T cells that neither killed nor produced antiviral factors. Since most HIV-1-infected people lack T-helper $\left(\mathrm{T}_{h}\right)$ responses to the virus, CD8 $\mathrm{T}$ cell function could be similarly impaired. In less immunocompromised patients, HIV-specific CD8+ $\mathrm{T}$ cells are sometimes able to produce a full range of antiviral cytokines and chemokines on encounter with antigen, but are characterised by low levels of perforins, a key mediator of cytolysis. This is associated with inefficient target cell killing and a cellsurface phenotye previously thought to indicate immature T cells[17].

In the case of HIV-1 infection, a small proportion of individuals termed long-term nonprogressors (LTNPs) are able to maintain their CTL responses. In contrast to progressors, LTNPs also maintain CD4 related HIV responses[18]. Recent research has shown that they do in fact have increased and maintained expression of perforins associated with their CD8+ HIV-specific T cells[19]. Furthermore, since the first description of the antiviral factor secreted by CD8 T cells (CD8 antiviral factor, $\mathrm{CAF}$ ), it has been recognised that soluble factors can inhibit viral replication. Previous studies had indicated that $\beta$-chemokines (CCL-3, -4, -5) may account for CAF's antiviral properties by competing with HIV-1 for binding to CCR5. However, such factors could only inhibit R5 viruses, and not X4 strains which utilise CXCR4 as their entry receptor. Using protein- chips and comparisons of mass spectra from patients with known different rates of progression, it has recntly been elegantly demonstrated that the a-defensins enable much of the anti-HIV activity of soluble factors from stimulated CD8 $+\mathrm{T}$ cells that is not attributable to $\beta$ chemokines[20]. Depletion of these molecules from culture supernatants eliminated activity against both $\mathrm{X} 4$ and R5 viruses and synthetic a-defensins were shown to reduce HIV-1 replication in vitro. Further work has shown high levels of the heat shock protein receptor (part of the innate arm of the immune system) in LTNPs (Stebbing et al, In press), and the recent demonstration that sub-physiological concentrations of a-defensins binds the heat shock protein receptor in a specific, saturable and dose-dependent manner[21] appears to provide a unifying theory regarding maintenance of the CTL response in some individuals. Accordingly, the viral phenomenology of apparent unlimited complexity with its multiple strategies and systems of pathogenic progression and immune evasion can be simplified.

\section{The evolutionary response of HIV-1}

Due to the dynamic nature of its replication, HIV1 has evolved into multiple sub-types or clades which are partly shaped by evolutionary selective forces in 
the host (mainly the immune response)[22]. Intrasubtype diversity may be as large as $20 \%$ and intersubtype genetic distances as high as $35 \%$. Subtypes A, C and D have spread throughout Africa whereas subtype B is dominant in the US and Europe. The distribution of clade $\mathrm{C}$ viruses is now most widespread (responsible for most new infections worldwide including those in Asia) and vaccine developments require consideration of this[23].

The remarkable genomic plasticity of HIV-1 and mutation away from an immune response has been shown in a recent study using automated DNA sequencing of the reverse transcriptase gene in 473 HIV-1 infected individuals[24]. Certain polymorphisms were associated with particular HLA class I alleles, and in some cases they clustered around known sequences for epitopes recognised by cytotoxic $\mathrm{T}$ lymphocytes and their flanking regions involved in processing antigenic peptides. One viral epitope was mutated in all but one of the HIV-infected subjects whose $\mathrm{T}$ lymphocytes had the potential to recognise it in its original form. In that single instructive case where no mutation had occurred, treatment with antiretroviral therapy has been started within days after exposure to HIV. This finding suggests that early treatment may limit escape mutations by blocking viral replication. Indirect evidence that HIV-1 has evolved within humans to avoid recognition by $\mathrm{T}$ lymphocytes in the context of the most prevalent HLA class I allele, HLA-A2, has also been found. Infected HLA-A2 -positive subjects were less likely than subjects without this allele to harbour HIV-1 with escape mutations. This had been previously suggested by the finding that the most prevalent HLA class I alleles worldwide (HLA-A1, $\mathrm{A} 2$, and $\mathrm{A} 3$ ) rarely present the dominant epitopes in the HIV envelope protein to CTLs. When a dominant epitope in HIV mutates in a way that allows it to evade recognition by CTLs, a further population of $\mathrm{T}$ lymphocytes recognising subdominant, typespecific epitopes may arise. Since these T lymphocytes recognise infected targets poorly, and are often generated after the function of CD4 T cells has been compromised, their ability to control the infection may be impaired. Indeed, during chronic infection most HIV-specific CTLs are incapable of lysing HIV-infected cells when tested directly ex vivo (unlike those obtained from LTNPs) $[25,26]$.
HIV is an evolving pathogen that has only recently (on an evolutionary scale) infected humans [27]. Mutations that enable the virus to evade immune surveillance do not necessarily mean that it is evolving towards greater pathogenicity. For example, AIDS does not usually develop in the presumed original host (the chimpanzee), although recent evidence suggests that SIV had long since caused a selective reduction in intron orthologues of HLA class I alleles[28],[29]. However, the ability of the virus to evade recognition by CTLs appears likely to cause harm in humans by rendering the host' $\mathrm{s}$ immune system unable to control the infection[30],[31]. Indeed, individuals harbouring HIV with more escape mutations have been shown to have a level of viraemia one log higher than that of patients who were infected with HIV that lacked such mutations. These findings suggest that an important clinical benefit of early treatment of HIV infection may be to limit escape mutations, which occur only when the virus has a chance to replicate.

\section{Future work}

The impact of HIV-1 diversity on drug and vaccine development remains uncertain[22], [32]. The race appears to be against a whole team of fast runners as opposed to one single fast opponent, and our chances of fulfilling Clinton's 1997 declaration of a vaccine within 10 years may decrease in proportion to the number of competitors. The major biological obstacles to the development of a preventative vaccine are (i) the fact that HIV incorporates its DNA into active sites of the hosts? chromosomes, leading to persistent infection for the life of that cell, its progeny and often the destruction of those cells; (ii) the lack of a small, readily available animal model; (iii) the genetic variability of HIV meaning that an effective vaccine must be broadly active to prevent emergence of resistant viruses; and, (iv) the fact that HIV utilises the same immune activation pathways required for successful vaccination, for its own replication.

However, the development of all successful vaccines has relied on the fact that some individuals become infected and do not develop symptoms of disease and our understanding of these cases in HIV1 has increased enormously. In addition, some indi- 
Tab 1. Some of the phase I and phase I/II HIV preventative vaccine studies that are currently ongoing or awaiting recruitment (Adapted from http://chi.ucsf.edu/vaccines and http://www.iavi.org/trials/basicsearchform.asp).

\begin{tabular}{|c|c|c|}
\hline $\begin{array}{l}\text { Protocol and number of individuals } \\
\text { for recruitment }\end{array}$ & Status & Class \\
\hline \multicolumn{3}{|l|}{ Phase I trials } \\
\hline $\begin{array}{l}\text { HIV vaccine trials network026 } \\
\text { HVTN }(n=160)\end{array}$ & $\begin{array}{l}\text { Immunisations } \\
\text { complete }\end{array}$ & Canarypox vector (Clade B Env, Gag, Pro) \\
\hline HVTN039 $(n=110)$ & $\begin{array}{l}\text { Immunisations } \\
\text { complete }\end{array}$ & Canarypox vector (Clade B Env, Gag, Pro, RT, Nef) \\
\hline HVTN041 (n=87) & Ongoing & $\begin{array}{l}\text { Protein (Clade B Nef-Tat fusion protein + Env sub-unit); } \\
\text { AS02A adjuvant }\end{array}$ \\
\hline HVTN045 (n=30) & Imminent & DNA plasmid (Clade B Env, Gag, Pro, RT, Tat, Vpu, Rev) \\
\hline HVTN048 (n=42) & Imminent & DNA plasmid (poly-epitope: Gag, Pol, Vpr, Nef, Rev and Env) \\
\hline HVTN049 (n=168) & 2003 & DNA plasmids (Clade B Gag, Env); PLG adjuvant \\
\hline HVTN040 (n=96) & 2003 & VEE vector (Clade C Gag) \\
\hline HVTN044 (n=60) & 2003 & $\begin{array}{l}\text { DNA plasmids (Clade B Gag-Pol-Nef, Clade A, B, C Env); } \\
\text { DNA plasmid cytokine adjuvant (IL-1g) }\end{array}$ \\
\hline VRC4302 & Ongoing & $\begin{array}{l}\text { DNA plasmid (gag-pol in frame fusion expressing protease, } \\
\text { RT and integrase) }\end{array}$ \\
\hline ALVAC vCP205 & Ongoing & Canarypox containing (gp120-gp41 and pol fusion genes) \\
\hline HVTN046 (n=100) & 2003 & DNA plasmid (Clade B Env, Gag, Pro, RT, Tat, Vpu, Rev) \\
\hline To be announced & & $\begin{array}{l}\text { MVA vectors (Env, Gag, Tat, Rev, Nef, Pol) } \\
\text { DNA plasmid (Gag); DNA plasmid cytokine adjuvant (IL-12) } \\
\text { DNA plasmid (Gag) and peptides (poly-epitopic: Clade B Env, } \\
\text { Gag, Nef) } \\
\text { Non-replicating adenovirus vectors (Clade B Gag-Pol-Nef; } \\
\text { Clade A, B, C Env) } \\
\text { DNA plasmids (Clade C Gag, Env) }\end{array}$ \\
\hline \multicolumn{3}{|l|}{ Phase I/II and Phase II trials } \\
\hline HVTN203 $(\mathrm{n}=330)$ & $\begin{array}{l}\text { Immunisations } \\
\text { Complete }\end{array}$ & $\begin{array}{l}\text { Canarypox vector (protein subunit Clade B Env); Aluminium } \\
\text { hydroxide gel as adjuvant }\end{array}$ \\
\hline HVTN047/Merck015 (n=400) & Imminent & HIV-1 Gag DNA in non-replicating adenoviral vector \\
\hline HVTN042/ANRSVAC19 (n=180) & 2003 & $\begin{array}{l}\text { Canarypox vector (Env, Gag, Pro, RT, Nef) and lipopeptides } \\
\text { (poly-epitopic Gag, Pol, Nef) }\end{array}$ \\
\hline THO23/LAI-DID & Ongoing & $\begin{array}{l}\text { Recombinant envelope glycoprotein containing the gp160 } \\
\text { from HIV-1 E (primary strain) }\end{array}$ \\
\hline AIDSVAXB/E and B/B & Ongoing & Bivalent formulation of gp120 protein (Clade B) \\
\hline AIDSVAXB & Ongoing & gp120 protein subunit (Clade B) produced in CO cells \\
\hline To be announced & & DNA plasmids (Clade B Gag-Pol-Nef; Clade A, B, C Env) \\
\hline
\end{tabular}

Fig 4. Illustration of angiotensin II signal transduction pathways involving heterotrimeric G-proteins and tyrosine kinase cascades. 
viduals (termed exposed seronegatives, ESN) 'see the virus' but do not develop infection and study of the unmatched monogomous partners of HIV-1 positive individuals is already yielding valuable insights. The table (below) describes some of the current phase I and phase I/II HIV prophylactic vaccine trials in progress (adapted from the websites http:// chi.ucsf.edu/vaccines and http://www.iavi.org/trials/ basicsearchform.asp ). Many others including those under the auspices of the International AIDS Vaccine Inititative (IAVI) are also underway.

The host has many mechanisms of preventing infection, both remembering it has been previously infected and an evolutionary ancient system of innate immunity, which recognises danger signals indicating that the invader is potentially harmful or is causing tissue damage. It has only recently been recognised that this ancient system, the first line of defence, is preserved in complex organisms. Research endeavours in this area have unveiled new functions and a deeper understanding of the HIV-1 armamentarium. For example, cell fusion and complementary DNA subtraction experiments have shown that a non-permissive phenotype (ie resistance to HIV-1 infection) may be conferred by the cytidine deaminase HIV-vif binding protein CEM15 , that appears to be responsible for the innate antiviral phenotype of certain T cells[33]. As for many of the other factors mentioned (and not mentioned[34]) above, such entities may become targets for the development of new drugs to alter the course of infectivity and infection[35]. Genetic influences on the outcome of infection are increasingly recognised and studies investigating these are valuable because the devastating immunodeficiency observed is often out of proportion to the level of Th cell destruction; here, the precise mechanisms governing cell death still remain unknown. An understanding of the immune responses that control HIV1 in the context of individual host genetics and ever increasing viral diversity represents our best hope of a vaccine.

\section{ACKNOWLEDGEMENT}

We are grateful to Professor Brian Gazzard for his thoughts on the manuscript. The picture on the front cover is kindly provided by Geraldine Reilly and Bill Lindsay from Gilead UK.

\section{REFERENCES}

[1] Mathers CD, Sadana R, Salomon JA, Murray CJ, Lopez AD. Healthy life expectancy in 191 countries, 1999. Lancet 2001; 357(9269):685-91.

[2] Clark S. Experts predict global devastation due to HIV/ AIDS. Lancet 2002; 360(9327):45.

[3] Stover J, Walker N, Garnett GP, et al. Can we reverse the HIV/AIDS pandemic with an expanded response? Lancet 2002; 360(9326):73-7.

[4] Buve A, Bishikwabo-Nsarhaza K, Mutangadura G. The spread and effect of HIV-1 infection in sub-Saharan Africa. Lancet 2002; 359(9322):2011-7.

[5] Douek DC, Brenchley JM, Betts MR, et al. HIV preferentially infects HIV-specific CD4+ T cells. Nature 2002; 417(6884): $95-8$.

[6] Palella FJ, Jr., Delaney KM, Moorman AC, et al. Declining morbidity and mortality among patients with advanced human immunodeficiency virus infection. HIV Outpatient Study Investigators. N Engl J Med 1998; 338(13):85360 .

[7] Stebbing J, Gazzard B. Resistance in HIV. Journal of HIV therapy $2002 ; \mathbf{1 2 ( 4 ) : 1 8 1 - 5 . ~}$

[8] Gerrish P. The rhythm of microbial adaptation. Nature $2001 ; \mathbf{4 1 3 ( 6 8 5 3 ) : 2 9 9 - 3 0 2 .}$

[9] Stebbing J, Portsmouth S, Gazzard B. Virus-host interactions. Journal of the Royal College of Obstetricians and Gynaecologists 2002; 9(3):152-9.

[10] Walker BD, Korber BT. Immune control of HIV: the obstacles of HLA and viral diversity. Nat Immunol 2001; 2(6):473-5.,p> [11] Ho DD, Huang Y. The HIV-1 vaccine race. Cell 2002; 110(2):135-8.

[12] Nelson M, Portsmouth S, Stebbing J, et al. An openlabel study of tenofovir in HIV-1 and Hepatitis B virus co-infected individuals. Aids 2003; 17(1):F7-F10.,p> [13] Rowland-Jones S, Pinheiro S, Kaul R. New insights into host factors in HIV-1 pathogenesis. Cell 2001; 104(4):473-6.

[14] Schmitz JE, Kuroda MJ, Santra S, et al. Control of viremia in simian immunodeficiency virus infection by CD8+ lymphocytes. Science 1999; 283(5403):857-60.

[15] Allen TM, O' onnor DH, Jing P, et al. Tat-specific cytotoxic T lymphocytes select for SIV escape variants during resolution of primary viraemia. Nature 2000; 407 (6802):386-90.

[16] Lieberman J. Defying death-HIV mutation to evade cytotoxic T lymphocytes. N Engl J Med 2002; 347(15): 1203-4.

[17] Appay V, Nixon DF, Donahoe SM, et al. HIV-specific CD8(+) T cells produce antiviral cytokines but are impaired in cytolytic function. J Exp Med 2000; 192(1): 63-75.

[18] Imami N, Pires A, Hardy G, Wilson J, Gazzard B, Gotch F. A balanced type $1 /$ type 2 response is associated with long-term nonprogressive human immunodeficiency virus type 1 infection. J Virol 2002; 76(18):9011-23.

[19] Migueles SA, Laborico AC, Shupert WL, et al. HIV-specific CD8(+) $\mathrm{T}$ cell proliferation is coupled to perforin expression and is maintained in nonprogressors. Nat 
Immunol 2002; 3(11):1061-8.

[20] Zhang L, Yu W, He T, et al. Contribution of human alpha-defensin 1, 2, and 3 to the anti-HIV-1 activity of CD8 antiviral factor. Science 2002; 298(5595):9951000.

[21] Nassar T, Akkawi S, Bar-Shavit R, et al. Human alpha defensin regulates smooth muscle cell contraction: a role for low-density lipoprotein receptor-related protein/alpha 2-macroglobulin receptor. Blood 2002; 100(12): 4026-32.

[22] Malim MH, Emerman M. HIV-1 sequence variation: drift, shift, and attenuation. Cell 2001; 104(4):469-72.

[23] Gaschen B, Taylor J, Yusim K, et al. Diversity considerations in HIV-1 vaccine selection. Science 2002; 296(5577):2354-60.

[24] Moore CB, John M, James IR, Christiansen FT, Witt CS, Mallal SA. Evidence of HIV-1 adaptation to HLA-restricted immune responses at a population level. Science 2002 ; 296(5572):1439-43.

[25] Shankar P, Russo M, Harnisch B, Patterson M, Skolnik $\mathrm{P}$, Lieberman J. Impaired function of circulating HIVspecific CD8(+) T cells in chronic human immunodeficiency virus infection. Blood 2000; 96(9):3094-101.

[26] Lieberman J, Shankar P, Manjunath N, Andersson J. Dressed to kill? A review of why antiviral CD8 T lymphocytes fail to prevent progressive immunodeficiency in HIV-1 infection. Blood 2001; 98(6):1667-77.

[27] Korber B, Muldoon M, Theiler J, et al. Timing the ances- tor of the HIV-1 pandemic strains. Science 2000; 288 (5472):1789-96.

[28] de Groot NG, Otting N, Doxiadis GG, et al. Evidence for an ancient selective sweep in the MHC class I gene repertoire of chimpanzees. Proc Natl Acad Sci USA 2002; 99 (18):11748-53.

[29] Santiago ML, Rodenburg CM, Kamenya S, et al. SIVcpz in wild chimpanzees. Science 2002; 295(5554): 465.

[30] Kimata JT, Kuller L, Anderson DB, Dailey P, Overbaugh J. Emerging cytopathic and antigenic simian immunodeficiency virus variants influence AIDS progression. Nat Med 1999; 5(5):535-41.

[31] Goulder PJ, Brander C, Tang Y, et al. Evolution and transmission of stable CTL escape mutations in HIV infection. Nature 2001; 412(6844):334-8.,p> [32] Stebbing J, Portsmouth S. AIDS Vaccine Research. HIV and AIDS Current Trends 2002; 8(2):15-17.

[33] Sheehy AM, Gaddis NC, Choi JD, Malim MH. Isolation of a human gene that inhibits HIV-1 infection and is suppressed by the viral Vif protein. Nature 2002; 418(6898):646-50.

[34] Novina CD, Murray MF, Dykxhoorn DM, et al. siRNAdirected inhibition of HIV-1 infection. Nat Med 2002; 8(7):681-6.

[35] Hammer SM. Increasing choices for HIV therapy. N Engl J Med 2002; 346(26):2022-3. 